\title{
Talent Management in HR
}

\author{
Preeti Khatri (Corresponding author) \\ HCTM, Kaithal-Ambala Road, NH-65, Kaithal, Haryana (136027), India \\ Tel: 099968-56761Ｅ-mail: pkhatri2010@rediffmail.com \\ Shikha Gupta \\ HCTM, Kaithal-Ambala Road, NH-65, Kaithal, Haryana (136027), India \\ Tel: 098131-81836 E-mail: shikha_gupta40@yahoo.com \\ Kapil Gulati \\ HCTM, Kaithal-Ambala Road, NH-65, Kaithal, Haryana (136027), India \\ Tel: 09812-04737_E-mail: kgulati85@yahoo.com
}

Santosh Chauhan

GIMT, 7 kms. From Pipli, Kurukshetra-Ambala Road, Kurukshetra, Haryana (136118), India

Tel: 094165-70322_E-mail: schauhan_15@yahoo.co.in

Received: August 13, $2010 \quad$ Accepted: August 26, $2010 \quad$ doi:10.5430/jms.v1n1p39

\begin{abstract}
Managing talent in a global organization is more complex and demanding than it is in a national business-and few major worldwide corporations have risen to the challenge. The current business and economic environment is exposing a host of weaknesses in the talent management practices of many organizations, as well as the lack of a comprehensive understanding of skills, capabilities, key workforces and top talent.

Talent strategy is, in fact, as important as any other part of an organization's overall strategy, regardless of the business conditions. Unfortunately, the harsh glare of the downturn has exposed the fact that the talent planning and management capabilities of many organizations are not equal to the challenges that lie ahead. Smart companies will also keep an eye out for skilled workers who in good times may have been too difficult or expensive to attract but who are now available thanks to workforce reductions in other companies. It is easy enough to say that companies that can rally their people will have a better chance to thrive during and after the economic downturn. But effective talent management is not simply a matter of exhortation or charisma. Close, comprehensive and scientific analysis of the capabilities needed to achieve high performance is vital.

Talent management is a process that emerged in the 1990s and continues to be adopted, as more companies come to realize that their employees' talents and skills drive their business success. These companies develop plans and processes to track and manage their employee talent, including, attracting and recruiting qualified candidates with competitive backgrounds, managing and defining competitive salaries, training and development opportunities, performance management processes retention programs, promotion and transitioning.

The objective of this paper is to retain the employees by managing their talent in organization.

Keywords: Talent, Manage, Global, Strategy, Downturn, Employees, Skills

\section{Talent Management}

Talent Management, often times referred to as Human Capital Management, is the process of recruiting, managing, assessing, developing and maintaining an organization's most important resource- people. It's pretty clear that people are a business's most important asset and in this regard, organizations are seeking ways to build data-driven decision making platforms.
\end{abstract}


Let's begin with a clear definition of what Talent Management is. It can be said that integrated talent management is not a payroll system with some HR forms; it is not a recruitment system; and it is not a Performance Appraisal system. It could be HR Information System, but not by default. Technically, it's a framework of tightly integrated HR processes that assist in making informed decisions that support your strategic objective to be profitable and successful.

Variously called human capital management, employee relationship management and workforce management, among others, talent management is not a new concept, but one that in the past, corporations haven't been prepared to embrace. In most companies, functions such as recruitment and succession planning, learning and development, performance management, workforce planning, compensation and other HR or training functions have often been sequestered in departmental silos. While important individually, these programs are usually a loose conglomeration of HR initiatives with little connection to each other, little alignment with the organization's vital few business goals and little real way of measuring their bottom-line impact.

Talent management solutions relieves the stress of writing employee performance reviews (Figure-1) by automating the task and using your exact workflow. Organizations can establish and communicate critical corporate goals, measure employee performance improvement, and ensure that all levels of the organization are aligned - all working towards the same goals.

\section{The approach to Talent Management technology}

To meet the talent management demand, this "solution convergence" is taking several forms. Human resource management systems (HRMS) providers, already incumbent in many organizations, are beginning to create add-on applications that provide a strategic layer on top of the more administrative HR functionalities. However, according to a recent study by Gartner Inc., many companies found that these new applications, while integrating with the current HRMS infrastructure, are not as deep as the single talent management applications. The challenge for most of these companies, which are typically small and privately owned, is that they lack the resources to effectively develop a robust solution - or acquire one - beyond their own niche.

Another more realistic alternative for many organizations is learning management systems, which now are being adopted as a mainstream corporate application. For many industry watchers, it seems a logical step to start with incumbent learning management systems, which already include many talent management functions and are used across the enterprise (and often throughout the extended enterprise as well) on a daily basis.

\section{The time to move}

During the financial crisis, many organizations took necessary and accepted action on their headcounts. Whether it was freezing, cutting bonuses or even downsizing their total employment most saw these as reasonable responses to the drastic cut in demand that occurred throughout the first half of last year. But with the Asian recovery now in full swing, workers are expecting much more from their organizations. And they appear prepared to switch jobs in order to get it. Companies will be inundated with millions of young adults of working age. Kapil Sibbal, the then Indian minister for HR development described the situation by 2050 as a HR "meltdown". "There will be a huge HR deficit in the West while at the same time India will have the world's youngest population," Sibbal said. "India will boast 546 million people under the age of 25, more than the population of Europe". Strong talent management is likely to be the key difference for organizations as Asian economies move into what is expected to be a highly-competitive new phase. But while redirecting focus may be difficult or time consuming, there are significant long-term gains available for business.

"Workers who are given training opportunities for personal and professional development, and are well-compensated and fairly treated, will likely be happier, more motivated, and more productive as a result. HR must convince management this is an important business strategy regardless of the industry.

\section{Five rules to Manage Talent}

The recession of 2008/2009 has forced many organizations to reexamine their talent management approach, and the most forward-looking companies have not limited their changes to a knee-jerk reaction to the financial crisis. Leading companies have begun to account for all the different dynamics of talent that are affecting them now and that are anticipated to influence them in the future. They have systematically changed their approaches to reflect the coming reality of the next five years. According to Tower Watson's study, following five rules have been defined to manage talent:

Rule 1: There's never enough money. Invest differently to optimize results. There's never enough money — in good times and bad. Instead of spreading the wealth evenly, employers need to segment their talent pools and invest differently in each segment. Segmentation makes it easier to concentrate your money where it makes the most difference. 
For example, there might be a number of average performers within a critical skill that you need to retain. These could be employees you cannot afford to lose, even if they are not high-potential employees. Your money might be best spent in creating programs- communication, recognition, rewards or training — to help engage and retain them. There is no one right answer for how organizations should segment their talent. Different businesses and approaches to the market will dictate different segmentation and investment strategies. Most important is ensuring that your segmentation drives the appropriate long- and short-term investments and results.

Rule 2: If it doesn't measure business impact, it's just a distraction. Companies need to measure outcomes - whether in production, sales or talent management - that affect business success. A large, global pharmaceutical company recently analyzed its talent management program for measurable impact. The firm assigned a group of mid- and low-senior-level managers to review all 14 of its talent management processes and the different data elements collected. If the managers could not tie a process to its tangible impact on business performance, they eliminate the program. Those programs that could be tied to business performance were then massively simplified. Across the organization, the company went from having 14 separate programs to just three simpler processes. Shifting to this measurement-driven approach is fundamental to ensuring that talent management makes a real difference in the organization.

Rule 3: Let the numbers drive talent decisions. Most talent decisions are made on gut instinct.(Figure-2) Not only are there few systems out there with good data on recruitment, promotion and job performance, but also the management culture in many organizations permits an intuitive approach to hiring. While we praise those with a "good eye for talent," industry data show that many firms often make poor choices. Statistics about washouts among new recruits, failure of newly promoted executives and other human capital challenges abound, but many firms still lack systematically embedded, empirically based selection and promotion practices.

For example, a global manufacturing company recently wanted to determine how best to redeploy its people and production assets based on changes in the economy and shifts in global demand. HR initially took the traditional approach of talking to line leaders about how people should be redeployed and then came up with a plan. But the head of operations felt they could do better. The company launched a much more extensive data analysis to understand past demand patterns, conduct deeper skills analysis, and analyze economic indicators and a host of other elements. Based on these data, a new redeployment plan was created that cost the company less, saved more jobs, accomplished the redeployment faster and built the needed capacity in growing markets. Collecting talent data and creating profiles is not an overnight process. Leading companies have been collecting this information for four or five years now, and they are just starting to get data that are good enough to base decisions on. But the results are worth the wait. These companies are beginning to see much better hiring and retention results. High washout rates are declining, and transfer and promotion decisions have teeth to them now that data show how successful an employee might be in a new position.

Rule 4: Build adaptable skills. Prepare future leadership for any situation. (Figure-3)The trend to build adaptable skills has been in the works for some time, but the reasons behind the trend have been greatly solidified by the current financial crisis. For decades, talent searches focused on generic leadership skills: driving results, overcoming adversity and demonstrating superior communication abilities. During the recession, companies quickly learned that almost everyone could communicate. More important, while communication skills might help employees be more effective in their job, other competencies and skills have a more direct effect on business results. A Towers Watson global research study focused on these competencies. Among the Fortune 500 companies surveyed, remarkably consistent themes emerged. Many companies have come to realize that their traditional leadership competency models do not reflect what is needed to successfully address the rapid changes in the economy. Because of this, companies are shifting from a reliance on traditional skills and competencies to more flexible and adaptable skills.

Rule 5: Simplify performance management, and measure impact instead of goals many companies ask where to begin when redeveloping talent management. There is an obvious connection between getting day-to-day performance right and driving better company results - critically important in today's economic environment. What's more, goal setting and performance management are the two most direct ways for management to communicate with employees about objectives. Performance management also helps clarify an employee's role, while focusing employee development on competencies that determine the organization's success. Finally, by linking reward outcomes to individual performance, effective performance management allows employers to realize their philosophy surrounding pay for performance. When companies get performance management right, it can provide the foundation for other talent management processes. For instance, if employees align their goals with business goals, they will make better day-to-day decisions, which have an immediate impact on business performance.

\section{Talent Insights}

The RBL Group summarizes what can be a complex talent landscape into 11 key talent "insights" or activities that HR 
and general managers should pay attention to. (Figure-4) They are:

-Talent matters inside a company... and outside

-Talent requires individual ability.... and teamwork

-Talent should align competencies with strategy inside... and stakeholders outside

-Talent requires assessment both backward... and forward

-Talent comes from thoughtful investments... that integrates and focuses on customers

-Talent has to be mindful of, and gain the benefits from, individual differences (diversity)... and build unity

-Talent should focus on the A players and match them to A positions... but also pay attention to B players

-Talent requires not only competence and commitment... but also contribution

-Technology facilitates talent management processes... and connection among people

-Talent activities need to be measured... as do talent outcomes

-Talent efforts need to be owned by line managers... and architected by HR professionals

"Many of the managers had good intellect and good capability. It was not the ability to do it that was lacking, but the willingness to do it." When Unilever started it first, Balfour says, he wanted to ensure it was handled in the right way and that explains why he was involved in every single discussion. "At the top of Unilever, there were probably 50 managers, so I could easily do that. And that was because for many of these people, this was like the end of the world. They thought they were good, and now they were being told they weren't and they didn't have a job. So, I thought it was necessary to ensure that ultimately I had that discussion or they had a discussion with the chairman. In my view, what we were doing was injecting honesty into the conversation, and I think for some of those people that honesty had not taken place."

\section{Critical evaluation}

The unfavorable economic environment and job insecurity that fueled the recent spike in employee loyalty, compelling many employees to put their job search temporarily on hold, is now rapidly improving. It is inevitable that good talent will quickly start to be more open to career changes as soon as they perceive that market conditions are recovering. It is therefore crucial for businesses, now more than ever before, to take a long-term view of their talent management strategies and take proactive steps to set retention plans in place.

A critical starting point for employers is to consider which employees or groups are most at risk of resigning, by being fully tapped into the mood of their workforce. Businesses should encourage their managers to prioritize employee needs, sentiments and aspirations to not only retain their talent but further prepare them for ongoing change. Indeed, our experience reveals that many managers are out of touch with their employees or lack the skills to effectively lead them through change. Reviewing selection processes for leaders and ensuring there is appropriate emphasis on people leadership (Figure-5), change management and empathy must take precedence.

Organizations should also identify the business critical roles that will help drive recovery, review existing profiles for these roles and look to develop these skills internally, or establish a plan to upgrade their talent by ensuring the external talent pipeline is geared to meet demand. Organizations should also re-evaluate their Employee Value Propositions and consider how they can emphasize job security, training and development.

\section{Strategies to employ Talent}

Talent management is not a passing management fad. If anything, the need for talent management has intensified over the past years and it is now a critical strategy for any organization - large or small - going forward, observes Dion Groeneweg, CEO, The Cape Group.

1 The buy Strategy: Bringing someone in from the outside also helps facilitate change. "If a business desires a culture shift or needs to move quickly in a specific area then buying-in skills to hotwire this process is often a good option," says Rachael Baker, Head of Organizational Change and Development at TAC Europe.

2 There are several more arguments in favour of the 'build' side of the equation. William Meirs, Senior Search Consultant at The Church and Palfrey Group says employers should aim to get smart, enthusiastic and flexible people on their payroll, even if their existing skills are not an exact match for the roles required. Obviously, a major issue with nurturing talent is that organizations must have the right training and mentoring plans in place.

3 The cocktail mix: Most organizations will employ a mixture of build and buy efforts in their talent management 
strategies. The exact ratios used will depend on the individual employer's circumstances but experts warn that under-selling the 'build' part could lead to problems with retention. Mike Lehr, President of Omega Z Advisors, advises clients to restrict external hiring to $20 \%$. "If you do not have a good developmental strategy for your talent, then even your hired talent will tend to go stale," he says.

Think of talent brand as a talent "edge" with customers, suppliers and prospective employees.

For example:

-When a company hires Price Waterhouse Coopers, they expect people with strong technical expertise, relevant industry experience, and a focus on getting the right answer. They will be cautious, because risk reduction is their business.

-When you walk into an Apple store, you assume that the staff are tech savvy and exude Apple cool. And, you assume that bigger corporate Apple has the kind of creative, innovative staff that can keep coming up with products like i-Pod, i-Phone and now i-Pad.

-When you walk on a Southwest Airlines aircraft, you expect friendly people, not the grumpy, surly attendants that accost you on the major airlines.

Talent exists at all levels of an organization and your talent management strategy must encompass the breadth and depth of your company. Talent programs need to start with identifying the critical positions in your organization and then identifying the right people to fill these positions.

An approach called pivotal role analysis can help a company accurately evaluate which job families and roles have the most impact on business strategy and growth. Basically, it involves grouping the workforce into four broad categories. These categories are:

-Strategic: The role directly impacts the company's ability to achieve its strategy.

-Core: The role (typically, operational) is primarily focused on executing the strategy.

-Support: The role (typically, staff positions) is necessary, but may be able to be provided through less expensive, alternative staffing arrangements (e.g., outsourcing).

-Noncore: The role and skills no longer align with the company's strategic direction.

In India, the Manpower Staffing Services survey also reveals that only 13 per cent of employers in India reported difficulties in staffing. This compared well to other countries such as top ranked Mexico, Canada and Japan. However, headhunters in India have always lamented the talent shortage in specific industries, such as information technology. Speaking to reporters in Mumbai, software company Infosys' Head-HR, TV Mohandas Pai said that the lack of skilled engineers in India will significantly impact the growing IT sector and much must be done to improve the quality of available manpower. Approximately only 200,000 engineering graduates in India out of almost 500,000 graduates were qualified to find a better place in the IT industry.

\section{A global challenge}

Deloitte's survey 'Becoming a Magnet for Talent' was conducted across 60 countries and reveals that almost 70 per cent of the 1,396 human resources practitioners surveyed felt attracting new talent posed the greatest threat to competitiveness, followed by the inability to retain key talent (66 per cent) and incoming workers with inadequate skills (34 per cent). The survey findings are underscored by an International Labour Organization (ILO) report, which said the global economy is not generating sufficient employment despite relatively buoyant growth.

What can you do to build the talent brand of your organization?

1 Make sure employees know the behavior you expect. How often do you ask employees what they are trying to do when they deal with customers or colleagues? You can't communicate too often.

2 Tell stories and make heroes. The power of "employee of the week" is one part reward and recognition, ten parts education and communication. Are you getting the full benefit by sharing examples of what top employees do differently to deliver and reinforce the talent brand?

3 Assess potential employees based on the talent brand you need, not the usual suspects. How many organizations focus on where employees went to University, or their grades, test scores or other variables that are not very well related to what you really want - a consistent customer experience?

4 Train to the talent brand, not just the skill set. As I said in the last post, imagine the last time you dealt with a service provider that had all the technical knowledge you would ever need, and despite their technical skills, the experience was infuriating. Think customer experience. 
Try defining your company's talent brand. What are the skills and behaviors that define the talent your organization needs to achieve its goals and ambitions? Let me know how it works!

\section{Conclusion}

Harvard Business Review points out that, in the best of talent management programs, organizations "integrated talent management, succession planning and leadership development into the company's strategic business processes. When the process runs smoothly, [companies] have a clear sense of whether their leadership teams will be able to execute on future strategic initiatives."

It is management, therefore, not HR, who should feel responsible for ensuring that the company defines clear job roles outlining necessary skill levels and competencies for each - and determine the appropriate incentives, rewards and compensation and set the metrics by which success will be measured. In many leading organizations, management establishes the necessary parameters which ensure that the organization has the right person with the right skills in the right job at the right time to reach strategic goals at all levels.

Whether corporate leadership will make the investments in time to drive a successful talent management program throughout the company? In the final analysis, though, it seems logical that businesses only stand to benefit from the resurgence of talent management techniques and technologies.

"Properly thought through," concludes the Harvard Business Review, "talent management can be a major part of a company's value proposition and a distinct competitive advantage." One thing to consider is that your strategies must be flexible enough to address employee age, culture and personalities, globalization, industry consolidation and, the near-perfect communication and connectivity that social software delivers.

\section{References}

Cheese, P., Farley, C. S., and Gibbons, A. The new talent equation, [Online] Available:

www.accenture.com/.../Accenture_Outlook_The_New_Talent_Equation.pdf

Current Research in Talent Management, [Online] Available:

http://www.insala.com/Articles/talent-management/current-research-in-talent-management.asp (December 01, 2005).

Howell, Paul (2010), Time for action - Talent managers get a wake-up call, [Online] Available:

http://www.hrmasia.com/resources/talent-management/time-for-action-talent-managers-get-a-wake-up-call/46153 (02

Jun 2010)

Lawler III, Edward E (2008) ‘Why are we losing all our good people?'Harvard Business Review June 2008, p.41

Nohria, Nitin; Groysberg, Boris; Lee, Linda-Eling (2008) 'Employee Motivation: A Powerful New Model'Harvard Business Review July/August, p. 78

One Page Talent Management, Effective HR Management Approach, Eliminating Complexity, Adding Value (2010) is published Harvard Business Press

Sandeep, V. (2010), Talent Management, [Online] Available:

http://www.coolavenues.com/search/google/mba\%20journal\%20human $\% 20$ talent $\% 20$ management?query=mba $\% 20$

journal\%20human\%20talent\%20management\&cx=003750404071188911528\%3Aboyfavopq9g\&cof=FORID\%3A9\&sit

esearch $=($ May 19, 2010)

Sims, Doris (2009). The Talent Review Meeting Facilitator's Guide

Talent Management - The New Silver Bullet?, [Online] Available:

http://www.talentmanagement101.com/downloads-wp-Talent-Management-Silver-Bullet.php

Talent Management, (HRfocus, August 2006) [Online] Available:

http://www.insala.com/Articles/talent-management/talent-management.asp (October 01, 2006). 
The Emergence of Talent Management - An Old Idea Gets New Life-, [Online] Available: http://www.talentmanagement101.com/downloads-wp-Emergence-Talent-Management.php

The New Employment Deal: How Far, How Fast and How Enduring Insights from Towers Watson's 2010 Global Workforce Study, [Online] Available: http://www.towerswatson.com/global-workforce-study www.successfactors.com/talent-management/articles/ - United States

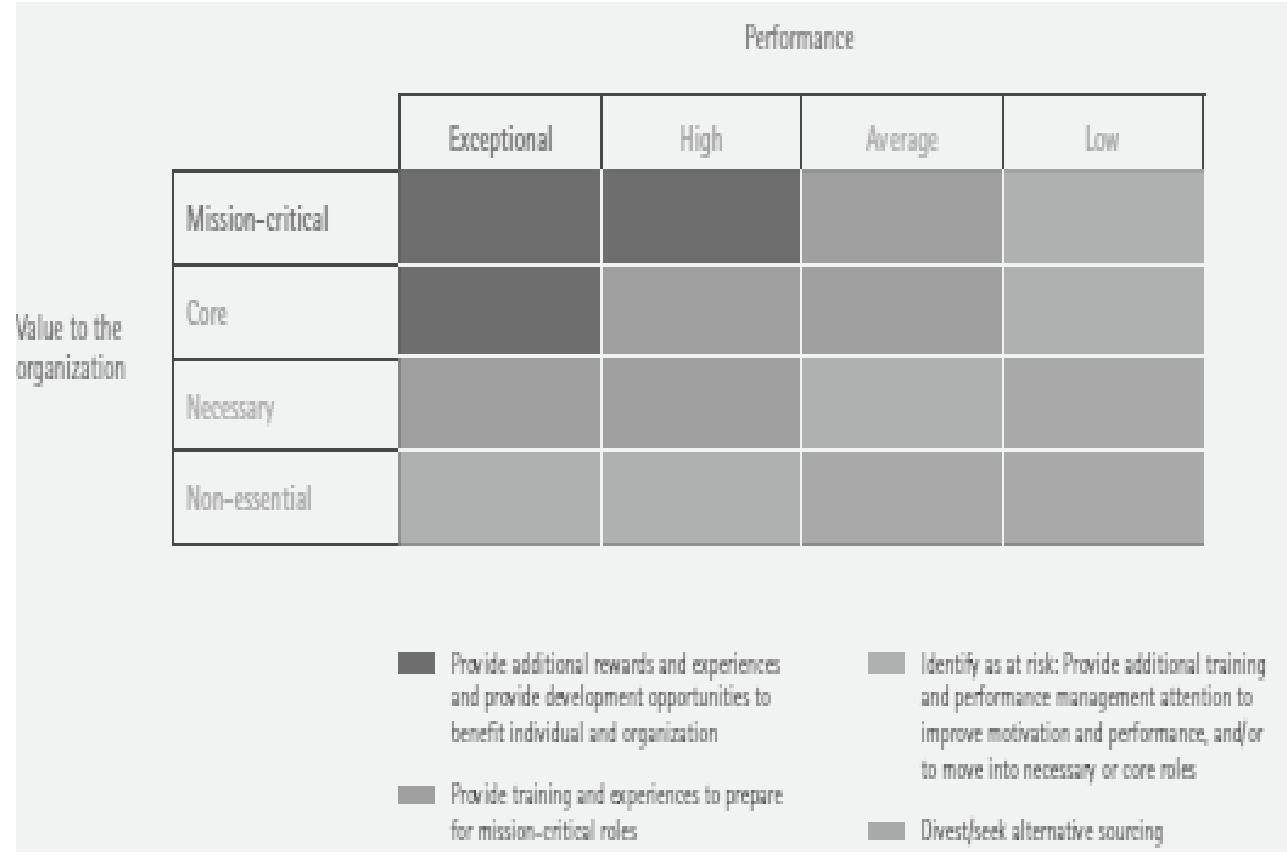

Figure 1. Performance Analysis Source- Accenture analysis

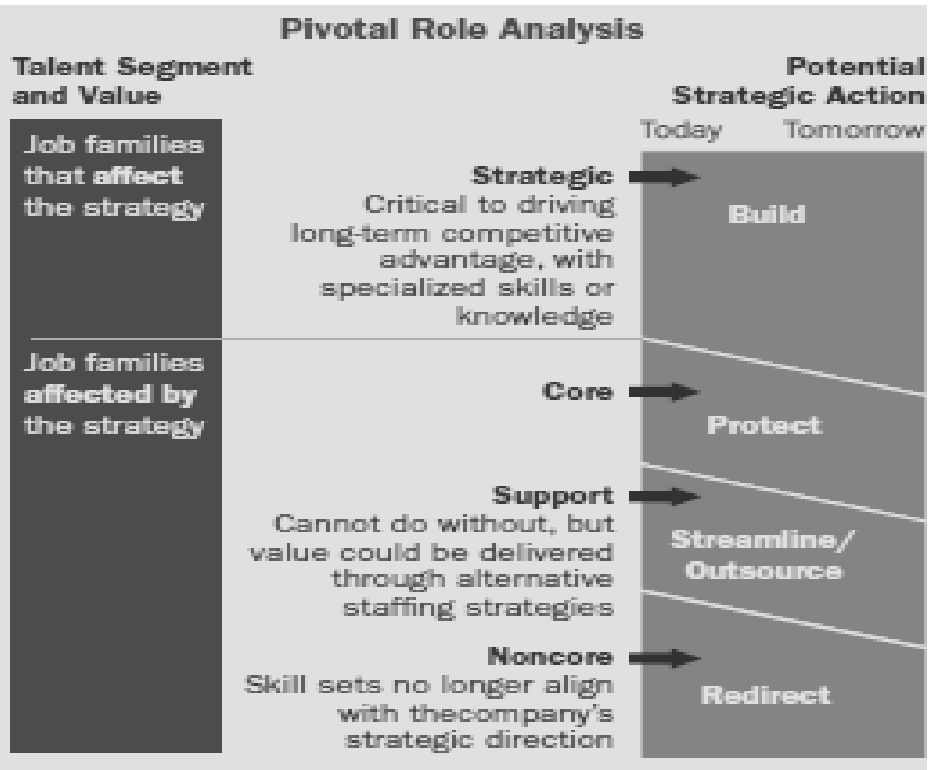

Figure 2. Pivotal Role analysis can strengthen Talent management decisions

Source- The Conference Board, Strategic Workforce Planning, 2006 


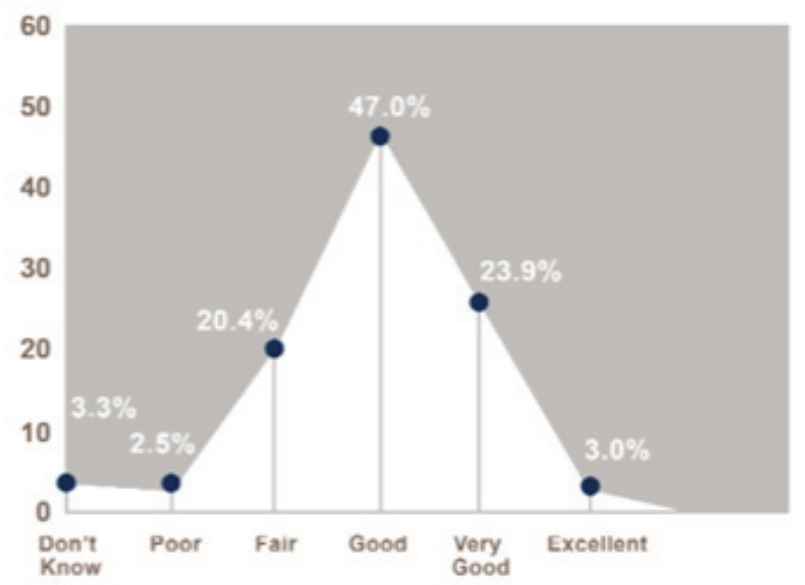

Figure 3. Evaluation of participants' own performance in growing leadership talent with their organisation

\begin{tabular}{|c|c|c|c|c|c|c|}
\hline & Excelient & Vary Good & Good & Fair & Poor & Dent Know \\
\hline Leaders overall & $10.4 \%$ & $34.9 \%$ & $35.1 \%$ & $15.3 \%$ & $3.8 \%$ & $0.5 \%$ \\
\hline $\begin{array}{l}\text { Internal candidates for } \\
\text { leadership roles }\end{array}$ & $3.8 \%$ & $26.7 \%$ & $38.2 \%$ & $22.4 \%$ & $7.9 \%$ & $1 \%$ \\
\hline $\begin{array}{l}\text { HR's ability to bring in } \\
\text { external candidates for } \\
\text { leadership roles }\end{array}$ & $2 \%$ & $9.2 \%$ & $31.1 \%$ & $34.9 \%$ & $19.6 \%$ & $3.1 \%$ \\
\hline Our talent strategy & $2.5 \%$ & $14.2 \%$ & $33.8 \%$ & $28.8 \%$ & $18.3 \%$ & $2.3 \%$ \\
\hline $\begin{array}{l}\text { Formal leadership } \\
\text { development efforts }\end{array}$ & $3.1 \%$ & $18.7 \%$ & $28.6 \%$ & $28.6 \%$ & $20.2 \%$ & $0.8 \%$ \\
\hline Early identification of talent & $3.3 \%$ & $13.5 \%$ & $28.3 \%$ & $34.2 \%$ & $19.4 \%$ & $1.3 \%$ \\
\hline $\begin{array}{l}\text { Information regarding } \\
\text { decisions of selection' } \\
\text { promotion }\end{array}$ & $2.3 \%$ & $10.9 \%$ & $29.3 \%$ & $35.4 \%$ & $20.1 \%$ & $2.0 \%$ \\
\hline $\begin{array}{l}\text { Link between compensation/ } \\
\text { rewards and leadership } \\
\text { performance }\end{array}$ & $2.3 \%$ & $17.3 \%$ & $30.5 \%$ & $29.3 \%$ & $18.8 \%$ & $1.8 \%$ \\
\hline
\end{tabular}

Figure 4. Participant evaluation of quality of talent $\&$ talent management initiative

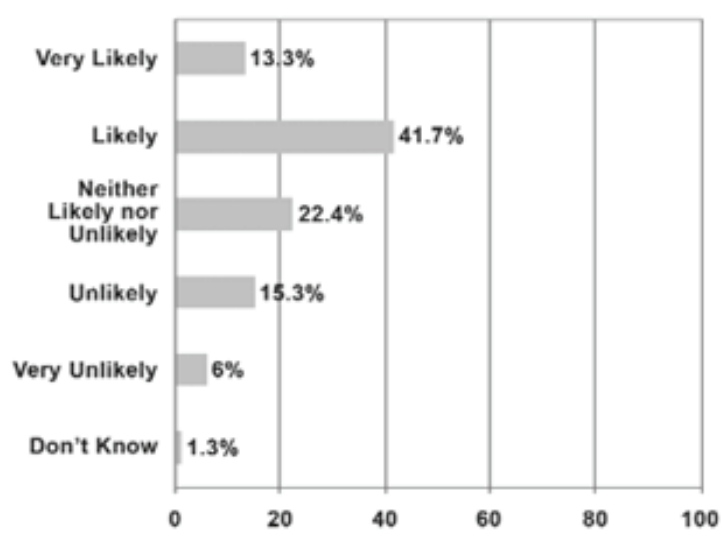

Figure 5. Likelihood organizational performance will suffer due to insufficient leadership talent 